\title{
A biomechanical comparison between the central one-third patellar tendon and the residual tendon
}

\author{
Matthew J Matava and William C Hutton \\ Department of Orthopaedics, Emory University School of Medicine, Atlanta, USA
}

\begin{abstract}
The purpose of this study was to compare the tensile strength of the central one third patellar tendon-as used for reconstruction of the anterior cruciate ligament- to that of the residual patellar tendon. Ten matched pairs of human cadaveric knees were used for this study, each specimen consisting of an intact patella-patellar tendonproximal tibial unit. One knee from each pair was randomly selected for removal of both the medial and lateral one third of the patellar tendon, leaving the central one third intact. The contralateral knee of each pair underwent removal of the central one third of the patellar tendon, leaving the residual two thirds intact. Each specimen was then mounted in a materials testing machine and tensile tested to failure at a strain rate of $100 \% \cdot \mathrm{s}^{-1}$. The most important result to emerge from these experiments was that there was no significant difference in maximum force to failure for the residual patellar tendon compared to the central one third. Thus any thought that removal of the central one third as a graft still leaves a tendon twice as wide and therefore twice as strong as a graft is dispelled by these experiments.
\end{abstract}

(Br J Sports Med 1995; 29 : 178-184)

Keywords : patellar tendon; knee ; anterior cruciate ligament

Currently, the most commonly used autogenous tissue for reconstruction of the anterior cruciate ligament (ACL) is the central one third of the patellar tendon. ${ }^{1}$ Advantages of this graft include its strength, ${ }^{2}$ its bone to bone fixation in host tissues, ${ }^{1}$ and its potential for revascularization. ${ }^{3}$ However, removal of the central one third of this tendon can lead to substantial morbidity to the extensor mechanism of the knee. ${ }^{4-7}$ Burks et al, using a dog model, found that the load to failure of the remaining two thirds of the patellar tendon was $70 \%$ of the control contralateral intact tendon at three months and $60 \%$ of the controls at six months. To our knowledge, no study exists regarding the biomechanical strength of the residual portion of the human patellar tendon following graft harvest.

Using clinical observation, we noted that the patellar tendon is not of uniform thickness across its width; rather, it appears more elliptical in cross-section. It was our hypothesis that removal of the central one third as a graft may not leave a residual tendon that is two thirds

Address for correspondence: Dr William C Hutton, Department of Orthopaedics, 2165 North Decatur Road, Decatur, Georgia 30033, USA of its original cross-sectional area, or of its original strength. Therefore the purpose of this study was to compare the tensile strength of the central one third of the patellar tendon to that of the residual two thirds. In this way, we attempted to determine whether the current graft width may contribute to the morbidity of the extensor mechanism of the knee by overly weakening the residual patellar tendon.

\section{Methods \\ Specimen preparation}

Ten matched pairs of human cadaveric knees were used to perform this study. The knees were obtained at the time of tissue harvest from subjects whose ages at the time of death ranged from 24 to 45 years. There were four males, three females, and three whose gender was not known to us. Each specimen consisted of an intact patella-patellar tendon-proximal tibial unit with the menisci and extensor retinaculum attached. The tissue was immediately stored fresh frozen at $-56^{\circ} \mathrm{C}$ until the time of preparation.

Before dissection, each knee was allowed to thaw at room temperature. The retinaculum, menisci, and distal quadriceps tendon were excised from their bony attachments. The paratenon was carefully removed from the underlying patellar tendon, as was the subjacent infrapatellar fat pad. The proximal tibia was cut so as to leave a $30 \times 30 \times 20 \mathrm{~mm}^{3}$ bone block with the patellar tendon insertion intact. The patella was not altered in any way. The preparations were covered in a saline soaked towel and then overwrapped with plastic wrap and aluminium foil to prevent dehydration. Any specimen with signs of articular cartilage degeneration or lack of integrity of the patellar tendon substance was not used.

One knee from each pair was then randomly selected for removal of both the medial and lateral one third of the patellar tendon (based on width measurements taken at the mid-length of the tendon) thus leaving the central one third intact (Figure 1). The length of the central one third segment was measured as the shortest distance between the two bone insertion sites. The thickness of the central one third was measured in the sagittal plane at a distance halfway along its length and midway across its width. Tendon dimensions were measured to the nearest millimetre with a hand held 
caliper while applying $10 \mathrm{~N}$ of longitudinal tension. The excised portions of tendon were removed from each insertion side and discarded. The tendinous insertions into the bone were left intact only along the width of the remaining tendon structures. ${ }^{*}$

The contralateral knee of each pair subsequently underwent removal of the central one third of the patellar tendon, leaving the residual two thirds tendon intact (Figure 2). The length of the residual tendon was measured as the shortest distance between the two bone insertion sites. Residual tendon width was measured as the combined width of both strands of the remaining patellar tendon at a distance halfway along the length of the tendon. Residual tendon thickness was measured halfway along the length of the remaining tendon

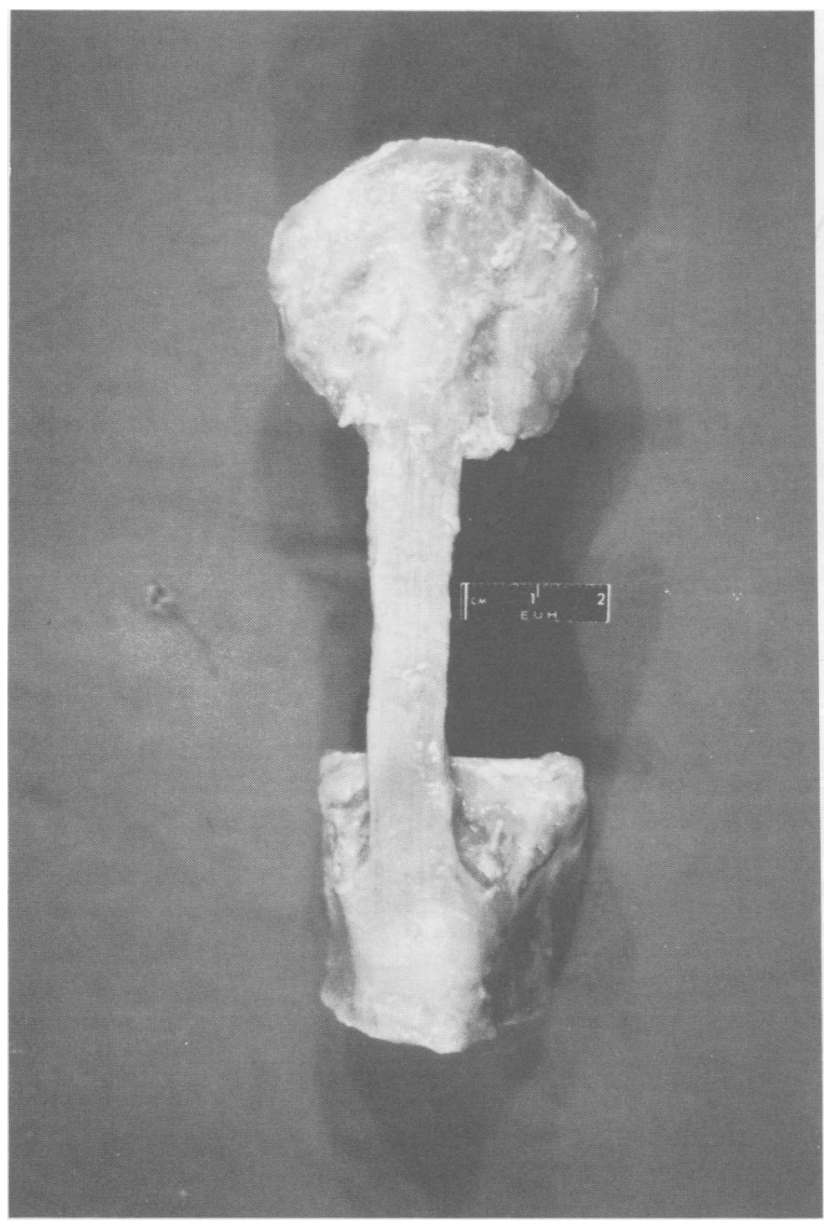

Figure 1. The central one third patellar tendon with attached bone blocks

\footnotetext{
* Initially, we intended to perform the tensile tests with the central one third of the patellar tendon attached to $25 \times 10 \times 10 \mathrm{~mm}^{3}$ patellar and tibial bone blocks as used in a typical ACL reconstruction. Unfortunately, in a series of preliminary experiments using that size of bone blocks, some of the blocks were unable to sustain the high forces necessary to rupture the tendon; with the application of the tensile force, they crumbled inside the clamps. Therefore, we were forced to use a bone-patellar tendon-bone unit that we could grip to withstand these high forces. This meant leaving the patella undisturbed and using a larger $\left(30 \times 30 \times 20 \mathrm{~mm}^{3}\right)$ tibial bone block.
}

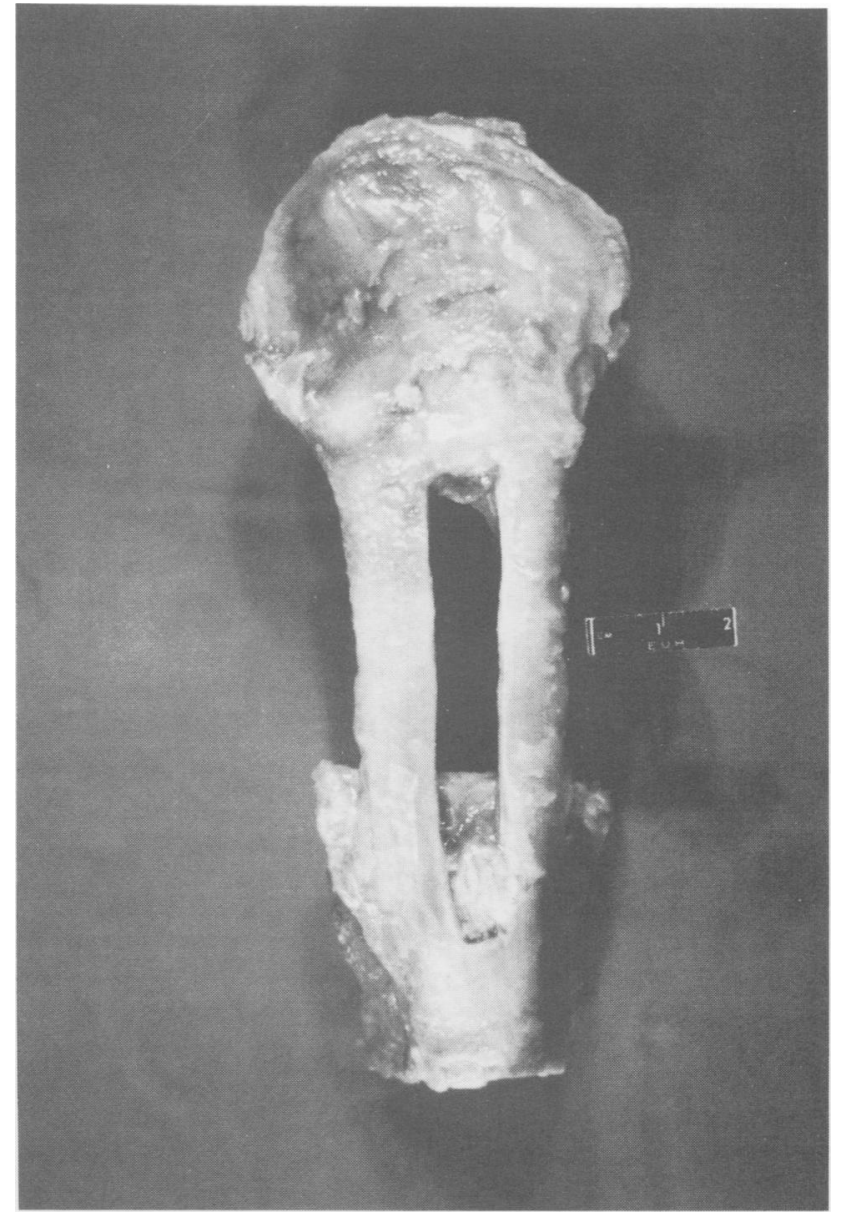

Figure 2. The residual patellar tendon with attached bone blocks, following removal of the central one third

strands and midway across their width. No removal of bone was attempted, nor was the resulting tendon defect surgically closed. Cross-sectional area was calculated as tendon width multiplied by thickness for both the central one third and residual patellar tendons. An area micrometer was not used for cross-sectional area calculation, as has been reported, ${ }^{29}$ as we sought to reproduce in vivo loading conditions of tendon failure which would necessitate that area (and therefore, stress to failure) calculations be performed with a fully hydrated tendon. The use of an area micrometer would have negated the effect of a fully hydrated tendon and may, therefore, have given artefactually high values for maximum stress.

\section{Mounting}

Each tendon preparation was mounted in a specially designed testing apparatus which allowed free passage for the patellar tendon while holding the bone ends secure. The patella was gripped in a device similar to that described by Ang et al. ${ }^{10}$ The jaws of the device were wedge shaped and could be approximated with the patella in between (Figure 3). As tension was applied to the patella, the bone became self locked without crushing. The tibial bone block was secured in a steel cage by means of a vertically oriented clamping screw, 


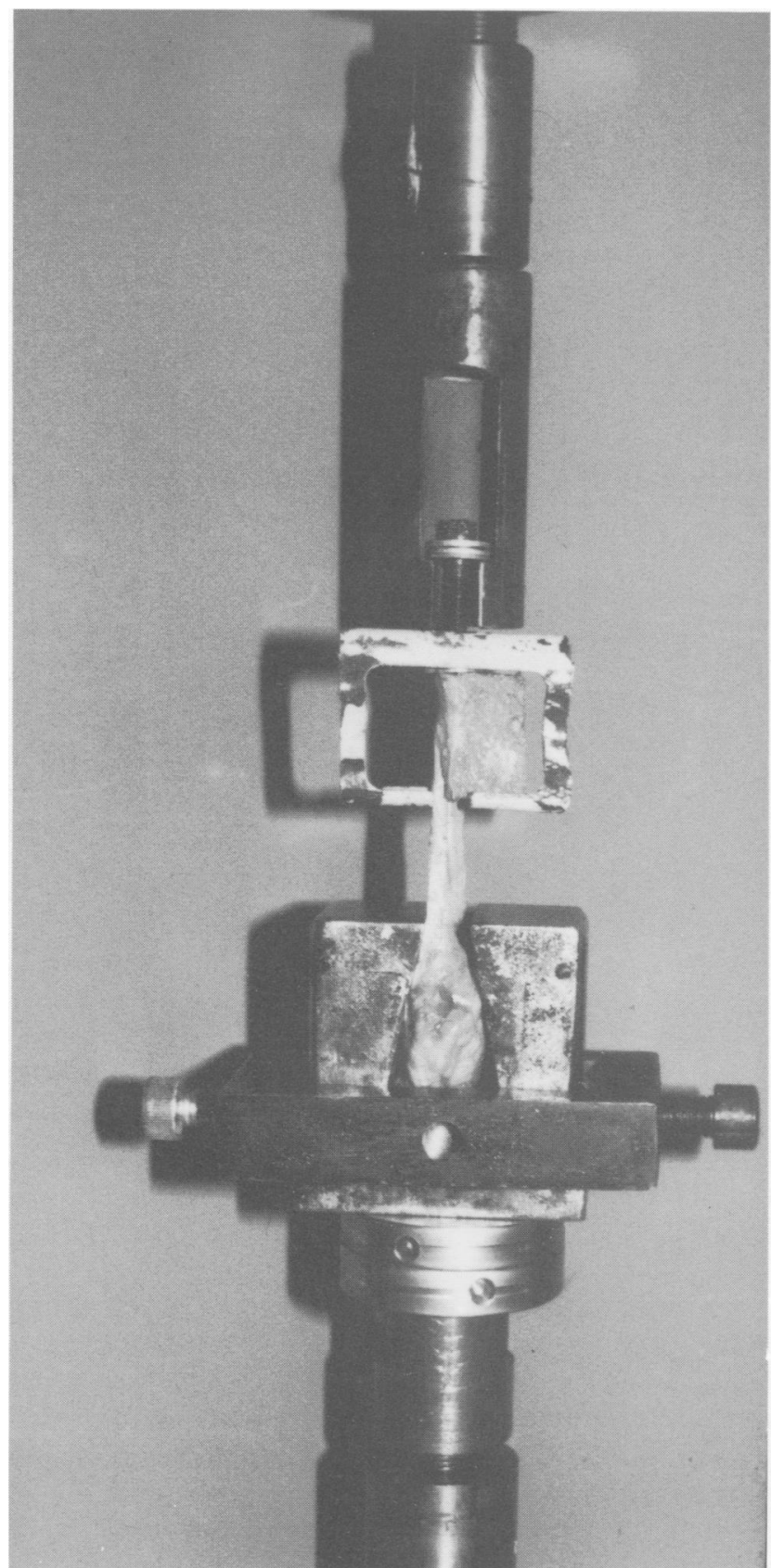

Figure 3. Tendon specimen mounted in the gripping apparatus before tensile testing. The bottom clamp is holding the intact patella and the top clamp is holding the shaped tibial bone block

which prevented rotation or displacement of the block (Figure 3).

\section{Mechanical testing}

The tensile failure tests were conducted on an MTS 810 servohydraulic test system (Materials Test System, Minneapolis). Both the central one third and residual patellar tendons were then loaded to failure in tension at a high strain rate of $100 \% \cdot \mathrm{s}^{-1}$ by scaling actuator stroke length to the initial length of the tendon. (This rate approximated $5.0 \mathrm{~cm} \cdot \mathrm{s}^{-1}$ ). This strain rate has been used previously ${ }^{2}{ }^{11}$ in order to reproduce the rapid loading conditions sustained by the ACL during in vivo failure.

Material properties measured were maximum force, maximum stress, and maximum force per unit width. Maximum force was defined as the force sustained by the specimen at failure, and was determined directly from the MTS load cell. Maximum stress was calculated as maximum force divided by the measured initial crosssectional area of the central one third or residual tendon. Maximum force per unit width was defined as the maximum load sustained by the specimen divided by initial width. No attempt was made to measure the modulus, stiffness, or energy to failure of the specimens because of our uncertainty regarding the extent of settlement of the bone blocks at the bone-grip junction during tensile testing, as has been shown to occur ${ }^{2}$ (settlement would artefactually increase the deformation recorded by the MTS load cell). The mode of failure (for example, mid-substance tendon tear or bone avulsion) was recorded for each specimen tested.

The load/displacement data taken from the MTS were recorded on an IBM XT computer using an Isaac Data Acquisition System (Cyborg) with a data acquisition speed of 500 point pairs per second. The accuracy of analogue to digital conversion was 12 bits. Graphic data were plotted on Lotus 1-2-3 Software.

\section{Statistical methods}

Statistical analysis was performed on SAS Statistical Software (SAS Institute). The paired Student's $t$ test and Wilcoxon signed rank test were used to compare the central one third and residual patellar tendons for maximum force and maximum stress values, respectively. Contingency table analysis was performed to assess statistical significance between the mode of failure and specimen type. Linear regression analysis was used to evaluate the relationship between tissue area versus maximum force sustained by both the central one third and residual patellar tendons. All statistical calculations were performed by a statistician.

\section{Results}

\section{Tissue macrostructure}

Grossly, all of the intact patellar tendons showed narrowing in the coronal plane between the patella and tibial insertion site (Figure 4). All of the tendons appeared somewhat elliptical in the transverse plane; sequential transverse cuts along the length of some extra tendon pairs confirmed this elliptical tendency in cross-section (Figure 5). (We are using 'elliptical' to describe the shape roughly.) As the thickness dimensions in Table 2 show, the tendon often had parallel sides (the thickness dimensions for the central one third and the residual were often the same) until at the edges it showed an elliptical finish). The patellar tendon insertion at the inferior pole of the patellar was broad and thin compared to the thick, hemispherical attachment at the tibial tubercle (Figure 5). A parallel arrangement of tendon 


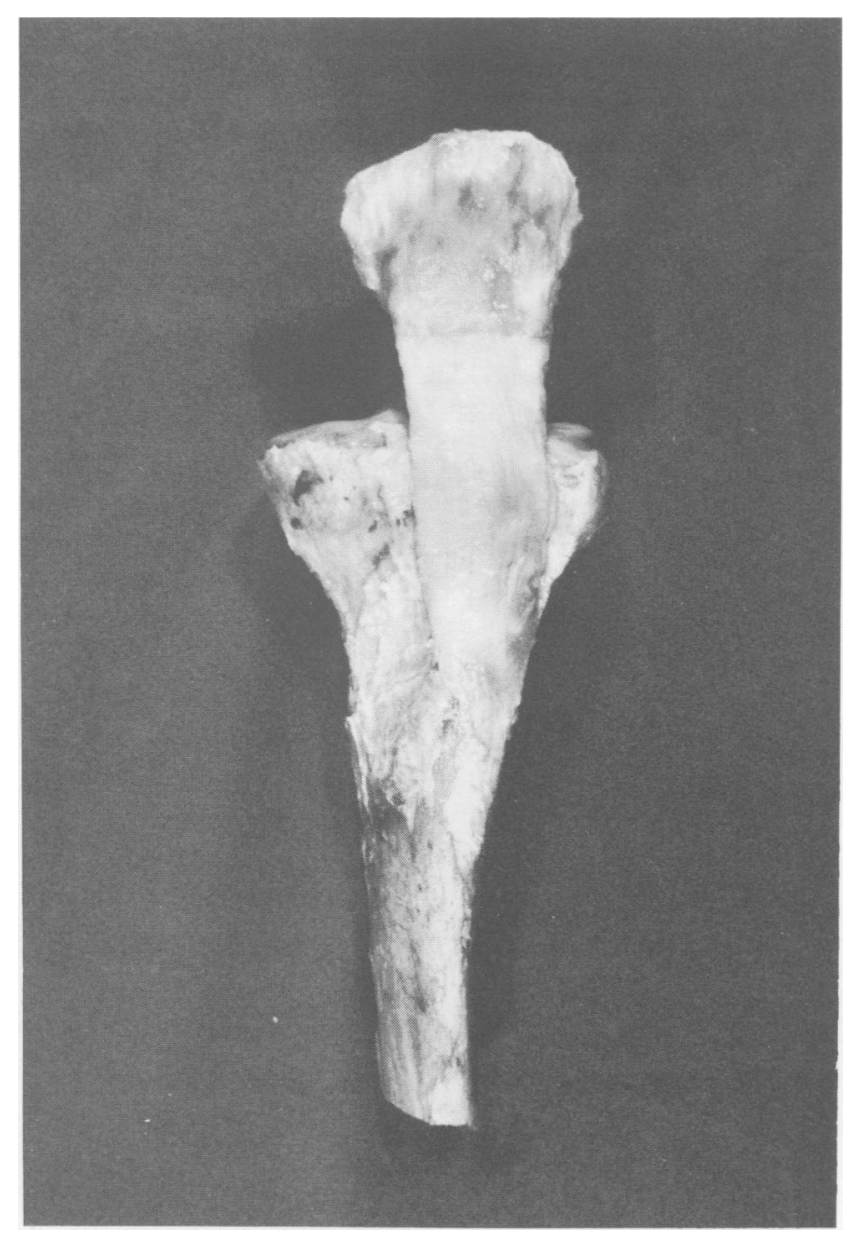

Figure 4. The patella-patellar tendon-proximal tibial unit before removal of tendon substance. Note the tapering configuration of the patellar tendon from proximal to distal

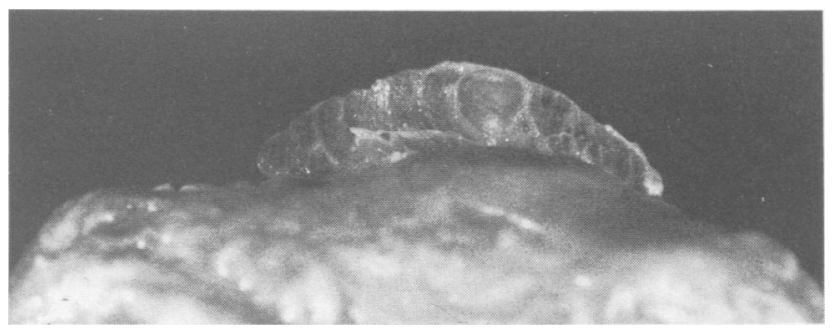

Figure 5. Cross-section of the patellar tendon insertion at the tibial tubercle. Note the thick, semilunar configuration at the attachment site and the elliptical cross-section

fibre bundles was noted over the entire width and throughout the complete length of the tendons. This was most clearly evident in the mid-substance of the tendon.

\section{Tìssue dimensions}

Tissue dimensions of the central one third and residual patellar tendons are shown in Table 1. Length measurements showed the most variability between specimens. This variability was seen even between knees from the same donor (Table 2). Some of the residual tendon strands were also slightly asymmetrical in length (that is, longer on one side than the other). All specimens varied between 3 and $4 \mathrm{~mm}$ in thickness.

\section{Mechanical testing}

Tensile failure properties of the central one third and residual patellar tendons are shown in Table 2. Maximum force values were greater in the residual tendon group, although this difference was not statistically significant. Conversely, both the maximum stress and maximum force per unit width were significantly greater in the central one third group than the residual tendon group ( $P=0.025$ and $P=0.013$, respectively). These two values for the central one third group were, on average, over 1.5 times greater than the corresponding values for the residual patellar tendon group. Typical force-elongation curves from specimens of both the central one third and residual patellar tendons are shown in Figures 5 and 6, respectively. Linear regression analysis showed no significant relation between specimen area and maximum force for the central one third or residual patellar tendons.

No attempt was made to examine the relationship between specimen age and maximum force or mode of failure, because of incomplete data records regarding age.

\section{Modes of failure}

Four primary modes of tensile failure were sustained by the 20 specimens (Table 1). There were nine tibial avulsions $(45 \%)$, five mid-substance ligamentous tears $(25 \%)$, three patellar avulsions ( $15 \%)$, and three with combined modes of failure (bone avulsion and midsubstance tear) (15\%). Ligamentous failure was characterized by rupture of the tendon substance, and was not localized to one specific area. Avulsion fractures occurred in the cancellous bone immediately beneath the dense cortical bone at the tendon insertion sites. The exposed cancellous bone showed no signs of osteopaenia or alteration in trabecular architecture. Contingency table analysis revealed no significant relationship between each of the four modes of failure and specimen type. Interestingly, bone avulsions occurred in nine of the 10 specimens in the central one third group.

\section{Discussion}

There are two important results to emerge from these experiments. The first is that the residual two thirds tendon was not significantly stronger than the central one third. Thus any thought that removal of the central one third as a graft still leaves a tendon twice as wide, and therefore twice as strong as the graft, is dispelled by these experiments. Clearly, the fact that the intact patellar tendon is somewhat elliptical in cross-section could play some role in explaining this finding. Because the central one third contained the thickest portion of 
Table 1. The tissue characteristics, maximum force, and mode of failure results for all tendon specimens

\begin{tabular}{|c|c|c|c|c|c|c|c|c|}
\hline \multirow[b]{2}{*}{ Donor } & \multirow[b]{2}{*}{ Age/sex } & \multirow[b]{2}{*}{ Knee } & \multirow[b]{2}{*}{ Side } & \multicolumn{3}{|c|}{ Tissue dimensions $(\mathrm{mm})$} & \multirow{2}{*}{$\begin{array}{l}\text { Maximum } \\
\text { force }(N)\end{array}$} & \multirow[b]{2}{*}{ Mode of failure } \\
\hline & & & & Length & Width & Thickness & & \\
\hline \multirow[t]{2}{*}{13} & $38 / \mathrm{M}$ & Central & $\mathbf{L}$ & 46 & 11 & 4 & 792 & Tibial avulsion \\
\hline & & Residual & $\mathbf{R}$ & 48 & 20 & 4 & 2109 & Mid-substance \\
\hline \multirow[t]{2}{*}{2} & $26 / M$ & Central & $\mathbf{R}$ & 52 & 10 & 4 & 1571 & Tibial avulsion \\
\hline & & Residual & $\mathrm{L}$ & 48 & 20 & 4 & 2145 & Mid-substance \\
\hline \multirow[t]{2}{*}{3} & $44 / F$ & Central & $\mathrm{L}$ & 47 & 8 & 4 & 579 & Tibial avulsion \\
\hline & & Residual & $R$ & 50 & 24 & 3 & 2029 & $\begin{array}{l}\text { Patellar avulsion and } \\
\text { mid-substance }\end{array}$ \\
\hline \multirow[t]{2}{*}{4} & $45 / F$ & Central & $\mathrm{L}$ & 48 & 10 & 4 & 668 & Tibial avulsion \\
\hline & & Residual & $\mathbf{R}$ & 45 & 20 & 4 & 587 & Tibial avulsion \\
\hline \multirow[t]{2}{*}{5} & $40 / F$ & Central & $\mathrm{R}$ & 40 & 10 & 4 & 1268 & Tibial avulsion \\
\hline & & Residual & L & 48 & 16 & 3 & 1273 & Tibial avulsion \\
\hline \multirow[t]{2}{*}{6} & $? / ?$ & Central & L & 50 & 9 & 4 & 1584 & Tibial avulsion \\
\hline & & Residual & $\mathrm{R}$ & 51 & 19 & 4 & 1050 & Tibial avulsion \\
\hline \multirow{2}{*}{7} & $? / ?$ & Central & $\mathrm{R}$ & 43 & 9 & 4 & 2092 & Mid-substance \\
\hline & & Residual & L & 46 & 18 & 4 & 2118 & Mid-substance \\
\hline \multirow[t]{2}{*}{8} & $24 / M$ & Central & $\mathbf{R}$ & 40 & 8 & 4 & 2136 & Patellar avulsion \\
\hline & & Residual & $\mathrm{L}$ & 54 & 16 & 4 & 2154 & $\begin{array}{l}\text { Patellar avulsion and } \\
\text { mid-substance }\end{array}$ \\
\hline \multirow[t]{2}{*}{9} & $? / M$ & Central & L & 42 & 11 & 4 & 1491 & Patellar avulsion \\
\hline & & Residual & $\vec{R}$ & 42 & 18 & 4 & 1655 & $\begin{array}{l}\text { Tibial avulsion and } \\
\text { mid-substance }\end{array}$ \\
\hline \multirow{2}{*}{10} & $? / ?$ & Central & $\mathbf{R}$ & 48 & 10 & 6 & 1936 & Patellar avulsion \\
\hline & & Residual & $\mathbf{L}$ & 50 & 16 & 4 & 1428 & Mid-substance \\
\hline
\end{tabular}

Table 2. Mean tensile failure properties of the central one third and residual patellar tensons. Values are mean (SD)

\begin{tabular}{lcccc}
\hline Specimen & No of specimens & $\begin{array}{c}\text { Maximum force } \\
(N)\end{array}$ & $\begin{array}{c}\text { Maximum stress } \\
(\mathrm{MPa})\end{array}$ & $\begin{array}{c}\text { Maximum unit width } \\
\left(\mathrm{N} \cdot \mathrm{mm}^{-1}\right)\end{array}$ \\
\hline Central one third & 10 & $1411.7(574.92)$ & $35.9(16.26)$ & $150.0(69.03)$ \\
Residual tendon & 10 & $1654.8(553.13)$ & $23.7(7.79)^{\mathrm{t}}$ & $89.5(30.39)^{*}$ \\
\hline
\end{tabular}

t Calculated as maximum force divided by combined area of both strands of the residual patellar tendon.

* Calculated as maximum force divided by combined width of both strands of the residual patellar tendon.

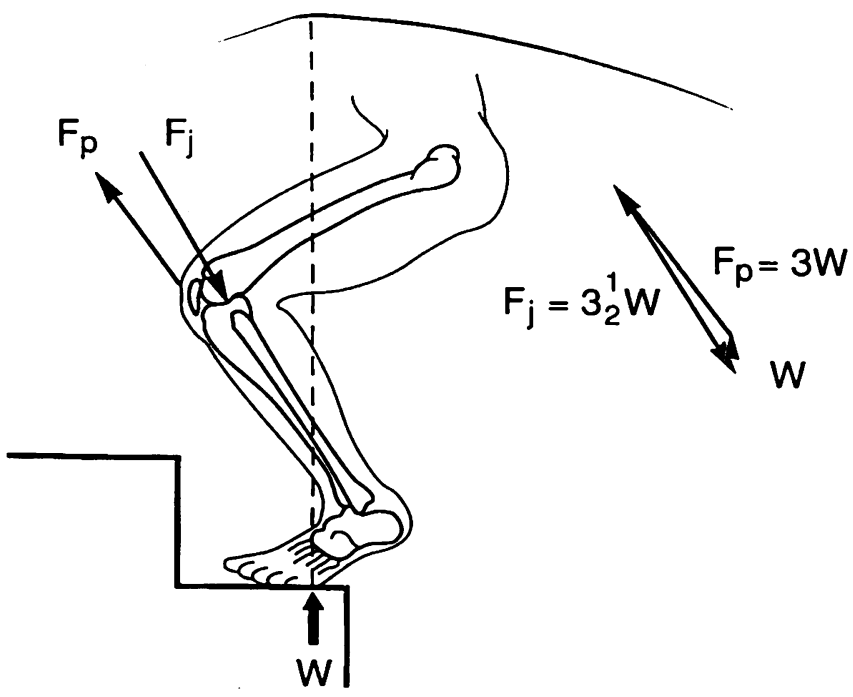

Figure 6. Free-body diagram and associated force triangle of the knee joint during one legged stance while stair climbing. If bodyweight $(\mathrm{W})$ acts through the foot, the patellar tendon force $(\mathrm{Fp})$ is three times body weight for the knee angle shown. Joint reaction force is represented by $\mathrm{Fj}$

the tendon overall, greater force per unit width was required to rupture this segment. We are unaware of any previous studies which have attributed clinical significance to the patellar tendon cross-section, al- though earlier investigators ${ }^{12} 13$ have illustrated the tendon's elliptical structure when describing the surgical technique of graft harvest.

The second important result from these experiments is that the residual tendon was found to be quite weak. Figure 6 illustrates how the act of stair climbing stresses the patellar tendon in tension to three times bodyweight. Therefore, a man with a body mass of $85 \mathrm{~kg}$ (equivalent to a force of $834 \mathrm{~N}$ ) can exert a tensile force of $2502 \mathrm{~N}$ on his patellar tendon. The highest experimental value we obtained was only $2154 \mathrm{~N}$. Clearly, either our samples were skewed to the low end of the population with regard to the tensile strength of the patellar tendon, or the residual tendon, in vivo, gains strength postoperatively by remodelling and regeneration. ${ }^{4}$

Limitations of this study include the use of large patellar and tibial bone blocks during testing. It would have been more clinically applicable to construct smaller rectangular bone blocks. However, as previously stated, some of these smaller bone blocks disintegrated inside the gripping devices during our pilot experiments. However, we were careful to remove all tendinous fibres from both the patellar and tibial insertion sites except where the tendon directly inserted into the bone, parallel to the fibres of the tendon substance. Our values for maximum force and maximum stress at failure for the central one third group are similar to the results reported 
by other investigators. ${ }^{29}{ }^{11}$ This would seem to confirm the validity of our testing method as well as the quality of our tendon specimens.

A second limitation involves the particular ages of the specimens tested. All specimens were between the ages of 24 and 45 years. We were unable to confirm the exact ages of four of the specimens. Noyes et $a l^{14}$ found that elastic modulus, strain energy to failure, and ultimate tensile stress were two to three times greater for younger specimens than for older specimens. In addition, older specimens tend to fail by bone avulsion, whereas younger specimens tend to fail by ligamentous disruption. The reasons for these age related changes are not known at present. We limited the upper age of the specimens tested to 45 years in an attempt to lessen the likelihood of age related strength reductions. No correlations were made between biomechanical properties and specimen age; therefore, age related effects are less likely to influence our results. In any case, our hypothesis related to a comparison across the same subject, and age is not relevant to this.

A further limitation is that our values for maximum stress were based on measurements of cross-sectional area of fully hydrated tendon strands. It is difficult to know how much the tendons were swollen when the cross-sectional measurements were taken. Thus the results for maximum stress must be viewed with circumspection.

Reconstruction of the anterior cruciate ligament using the central one third of the patellar tendon was initially described by Jones in $1963 .{ }^{17}$ Since that time, several studies have been published advocating the selection of this tissue option. ${ }^{125} 5131617$ The primary advantage of the patellar tendon graft is that it is the strongest of all currently available tissues. ${ }^{2}$ In addition, there exists the potential for graft revascularization through the adjacent synovial tissues, infrapatellar fat pad, and tibial remnant of the anterior cruciate ligament. ${ }^{3}$ Moreover, the attached bone blocks at either end facilitate graft union in the femoral and tibial metaphyseal bone. ${ }^{1}$ Complications associated with the use of this tissue have, historically, been limited to isolated cases of patellar tendon rupture ${ }_{18}^{18}$ patellofemoral spurring, ${ }^{4}$ medial and lateral patellar subluxation, ${ }^{16}$ and patellar fractures. ${ }^{19}$ The results of the present study help to explain why these complications are mainly centred on the residual patellar tendon; namely, that the residual tendon is a relatively weakened structure.

Despite the advantages of using the patellar tendon as a reconstructive graft, significant morbidity has been described related to disruption of the extensor mechanism of the knee following graft harvest. ${ }^{4-7}{ }^{16}$ Tibone and Antich ${ }^{7}$ noted a $15 \%$ quadriceps deficit on isokinetic testing two years after anterior cruciate ligament reconstruction with the patellar tendon graft. Rosenberg et $a l^{4}$ found consistent deficits in isokinetic and functional testing of the extensor mechanism in patients one to two years after reconstruction of the ACL with the central one third patellar tendon. Seto $\mathrm{et} \mathrm{al}^{6}$ examined 10 patients at an average of five years after intraarticular ACL reconstruction. Isokinetic quadriceps and hamstring muscle strength were tested at 120 and $240^{\circ} \cdot \mathrm{s}^{-1}$ using the Cybex dynamometer. The found, at $120^{\circ} \cdot \mathrm{s}^{-1}$, an average peak torque deficit of the quadriceps of $41 \%$ while the hamstring deficit was only $16 \%$. At $240^{\circ} . \mathrm{s}^{-1}$, the quadriceps mean peak torque deficit was $33 \%$, and $9 \%$ for the hamstring deficit.

Early on after implantation, there is a significant reduction in the initial strength of the patellar tendon graft over time. ${ }^{12}{ }^{20} \mathrm{By}$ one year, graft strength is approximately half that of an intact $A C L .^{12}$ Butler et al ${ }^{20}$ found that in the primate model one year after implantation, patellar tendon graft stiffness and maximum force were decreased to $57 \%$ and $39 \%$ of controls, respectively. Clancy et al ${ }^{12}$ tested patellar tendon graft strength following intra-articular reconstruction of the rhesus monkey ACL. Compared to intact controls, graft strength was noted to be $26 \%$ at three months and $52 \%$ at 12 months. Such observations may reflect an increased vascular response related to inflammation and cell death, as well as reorganization of the graft's colleagen and proteoglycan content. ${ }^{21}$ These events may also explain the increased incidence of graft rupture, in vivo, compared to rupture of the residual patellar tendon, which remains a vascular structure. Scar formation in the graft harvest site also may increase its tensile strength postoperatively. Therefore it could be inferred that graft width needs to be increased above $33 \%$ of the intact tendon width in order to lessen these problems. Our results suggest that these complications would only be transferred to the residual tendon.

Traditionally, mechanical strength testing of knee ligament preparations have involved tensile failure tests under high strain rate conditions. ${ }^{2} 9111420$ This is done in an attempt to approximate physiological loading conditions. It has been shown that at slow deformation rates the unit tested will frequently fail through bone avulsion, whereas at faster deformation rates there is an increased frequency of ligamentous failure. ${ }^{22}$ Our study was similarly conducted using fast strain rates of $100 \% \cdot \mathrm{s}^{-1}$. The primary mode of failure we observed was bone avulsion (patellar or tibial) in 12 out of 20 specimens. Our tests were carried out on tendon strands, not whole tendons, so it is difficult to draw comparisons with previous results. From a clinical standpoint, traumatic patellar disruption occurs most commonly at the tendon insertion sites proximally and distally, with disruption through the tendon substance particularly rate. ${ }^{23}$ The mid-substance tears that we noted sustained some of the highest maximum forces before failure, and were found predominantly in the residual tendon group (Table 2). This may have been due to the broader total area of the insertion sites present in this group, leading to a diffusion of load over a greater area, or by the fact removal of the central one third disrupted the fibres on the interior edges of the residual strands.

One interesting observation from this study was the narrowing of the intact patellar tendon distally; this has clinical relevance. When the central one third is removed for reconstruction of the anterior cruciate ligament, a fixed width of tissue (usually $9-11 \mathrm{~mm}$ ) is harvested. It follows that a greater proportion of tendon is removed distally than proximally; disruption across, rather between, the tendon fibres may result. This might weaken 
the residual patellar tendon by causing a stress-riser effect at its distal extent. We therefore suggest that the determination of graft width be made both proximally and distally, with the tendon borders used as a reference guide. In addition, graft harvest may best be performed with individual incisions between tendon fibres, not with the simultaneous dual parallel scalpel blades that are currently available.

In conclusion, harvest of the central one third of the patellar tendon as a reconstructive ACL graft leaves a residual tendon that is twice as wide as the graft, but not significantly stronger. This may be attributed to the diminished tissue thickness at the periphery of the residual tendon.

\section{Acknowledgements}

The authors wish to thank Richard Brown of the Georgia Institute of Technology and Stephanie Manuel MS for technical assistance; Michael $\mathrm{D}$ Rooks MD and W Scott Clark PhD for statistical analysis of the data. Lifelink Tissue Bank, Tampa, Florida, donated the patellar tendons.

\section{References}

1 Clancy WG, Nelson DA, Reider B, Narechania RG. Anterior cruciate ligament reconstruction using one-third of the patellar ligament, augmented by extra-articular tendon transfers. $J$ Bone Joint Surg (Am) 1982; 64-A: 352-59.

2 Noyes FR, Butler DL, Grood ES, Zernicke RF, Hefzy MS. Biomechanical analysis of human ligament grafts used in kneeligament repairs and reconstructions. J Bone Joint Surg (Am) 1984; 66-A: $344-52$

3 Arnoczky SP, Tarvin GB, Marshall JL. Anterior cruciate ligament replacement using patellar tendon. An evaluation of graft revascularization in the dog. J Bone Joint Surg $(A m) 1982 ; 64-A$ : 217-24.

4 Rosenberg TD, Franklin JL, Baldwin GN, Nelson KA. Extensor mechanism function after patellar tendon graft harvest for anterior cruciate ligament reconstructions. Am J Sports Med 1992; 20: 519-25.

5 Sachs RA, Daniel DM, Stone ML, Garfein RF. Patellofemoral problems after anterior cruciate ligament reconstruction. $A m J$ Sports Med 1989; 17: 760-65.

6 Seto JL, Orofino AS, Morrissey MC, Medeiros JM, Mason WJ. Assessment of quadriceps/hamstring strength, knee ligament stability, functional and sports activity levels five years after anterior cruciate ligament reconstruction. Am J Sports Med 1988; 16: $170-80$.
7 Tibone JE, Antich TJ. A biochemical analysis of anterior cruciate ligament reconstruction with the patellar tendon. Am J Sports Med 1988; 16: 332-35.

8 Burks RT, Haut RC, Lancaster RL. Biomechanical and histological observations of the dog patellar tendon after removal of its central one-third. Am J Sports Med 1990; 18: 146-53.

9 Butler DL, Kay MD, Stouffer DC. Comparison of material properties of fascicle-bone units from human patellar tendon and knee ligaments. J Biomechanics 1986; 19: 425-32.

10 Ang EJ, Wong HK, Goh J, Yuen WM, Balasubramaniam P. Device for tensile testing of rabbit patellar tendons. Med Biol Eng Comput 1989; 27 : 545-48.

11 Butler DL, Grood ES, Noyes FR, Zernicke RF, Brackett K. Effects of structure and strain measurement technique on the material properties of young human tendons and fascia. J Biomechanics 1984; 17 : 579-96.

12 Clancy WG, Narechania RG, Rosenberg TD, Gmeiner JG, Wisnefske DD, Lange TA. Anterior and posterior cruciate ligament reconstruction in rhesus monkeys. J Bone Joint Surg ( $\mathrm{Am})$ 1981; 63-A : 1270-84.

13 Jones KG. Results of use of the central one-third of the patellar ligament to compensate for anterior cruciate ligament deficiency. Clin Orthop 1980; 147: 39-44.

14 Noyes FR, Grood ES. The strength of the anterior cruciate ligament in humans and rhesus monkeys. Age-related and speciesrelated changes. J Bone Joint Surg $(A m)$ 1976; 58-A: 1074-82.

15 Insall J, Joseph DM, Aglietti P, Campbell RD. Bone-block iliotibialband transfer for anterior cruciate insufficiency. J Bone Joint Surg (Am) 1981; 63-A : 560-69.

16 Hughston JC. Complications of anterior cruciate ligament surgery. Orthop Clin North Am 1985; 16: 237-40.

17 Jones KG. Reconstruction of the anterior cruciate ligament. A technique using the central one-third of the patellar ligament. $J$ Bone Joint Surg $(A m) 1963$; 45-A : 925-31.

18 Bonamo JJ, Krinick RM, Sporn AA. Rupture of the patellar ligament after use of its central third for anterior cruciate reconstruction. J Bone Joint Surg (Am) 1984; 66-A: 1294-97.

$19 \mathrm{McCarroll}$ JR. Fracture of the patella during a golf swing following reconstruction of the anterior cruciate ligament. A case report. Am J Sports Med 1983; 11: 26-7.

20 Butler DL, Grood ES, Noyes FR, et al. Mechanical properties of primate vascularized vs. nonvascularized patellar tendon grafts; changes over time. J Orthop Res 1989; 7: 68-79.

21 McFarland EG, Morrey BF, An KN, Wood MB. The relationship of vascularity and water content to tensile strength in a patellar tendon replacement of the anterior cruciate ligament in dogs. Am J Sports Med 1986; 14: 436-48.

22 Noyes FR, DeLucas JL, Torvik PJ. Biomechanics of anterior cruciate ligament failure: an analysis of strain-rate sensitivity and mechanical failure in primates. J Bone Joint Surg $(\mathrm{Am}) 1974 ; 56-\mathrm{A}$ : 236-53.

23 Larson RL, Jones DC. Fractures and dislocations of the knee. Part II : dislocations and ligamentous injuries of the knee. In: Rockwood CA, Green DP, eds. Fractures in adults, volume 2, 2nd ed. Philadelphia: JB Lippincott, 1984: chapter 16. 